\title{
IMPACTO DOS FATORES DE INTERAÇÃO HOMEM-MÁQUINA NO ENTERPRISE RESOURCE PLANNING (ERP) SOFTWARE DESIGN
}

\author{
Impact of man-machine interaction factors \\ on enterprise resource planning (ERP)
}

\author{
Cagla Ozen ${ }^{1}$ \\ Nuri Basoglu² \\ Tugrul Daim ${ }^{3}$
}

\begin{abstract}
Enterprise Resource Planning (ERP) systems integrate processes and functions across the company by using a single data repository. Today ERP systems are not only accepted as simple software packages but a core engine of a framework for business processes. Since adopters of ERP systems have a great number of alternatives during the selection process, software vendors should differentiate their product. Various differentiation policies can be applied by software vendors to achieve competitive advantage in the market. This paper is focusing on one of these policies; area of man-machine interaction. In this study, first, adaptive and intelligent characteristics for the user interface of the ERP package were explored by conducting survey to ERP system end-users. In this survey, we primarily aim to understand and model the factors that are affecting end-user satisfaction with the ERP system and its interface design. The results indicate that ease of use (EoU) and usefulness are determinants of end-user satisfaction with ERP system and its interface design. This paper discusses these findings, the models that we were inspired while we had been forming our model, our model framework and finally describes future study opportunities about human and computer interaction analysis and prototyping studies in ERP systems.
\end{abstract}

${ }^{1} \mathrm{MS}$, Department of Management Information Systems, Bogazici University, Istanbul - Turkey ${ }^{2} \mathrm{PhD}$, Department of Management Information Systems, Bogazici University, Istanbul - Turkey ${ }^{3} \mathrm{PhD}$ Department of Engineering and Technology Management, Portland State University, Portland - Oregon

Rev. Adm. UFSM, SAnta Maria, v. I, N. 1, P. 26-36, Jan./ABr. 2008 


\section{Introduction}

In the last two decades, enterprise systems became a core part of the information systems architecture in a very large number of corporations [5]. ERP systems integrate information and information-based processes within and across functional areas in an organization [14].

Lonzinsky [16] claims that there are seven general objectives that adopters of ERP systems seek to accomplish by installing new enterprise software packages:

1. Drastically reduce the size and cost of the company's informatics sector;

2. Decentralize information processing by making data available in real time without dependence on the MIS department;

3. Provide technology tools that permit simplification of accounting, finance, and administrative functions, as well as the generation of management reports to maintain processes of control and business management;

4. Create a base to support growth with reduced proportional internal support costs;

5. Achieve a better balance between decentralization and control among functions to avoid duplication, ensure synergy, and manage performance indicators;

6. Electronically exchange information and orders with major clients to decrease costs;

7. Employ new technologies to keep pace with or surpass those of competitors.

Since adopters of ERP systems have a great number of alternatives during the selection process, software vendors should differentiate their product. Various differentiation policies can be applied by software vendors to achieve competitive advantage in the market. This paper is focusing on one of these policies; area of man-machine interaction. On the other hand, while millions of dollars have been spent on implementing ERP systems, previous research indicates that potential users may still not use those [3]. To address this gap in our study, first, adaptive and intelligent characteristics for the user interface of the ERP package were explored by conducting survey to 35 ERP system end-users. In this survey, we primarily aim to understand and model the factors that are affecting end-user satisfaction with the ERP system and its interface design.

The results and our model framework indicate that ease of use and usefulness are determinants of end-user satisfaction with ERP system and its interface design. Our model framework also demonstrates determinants of usefulness and ease of use. This paper discusses these findings, the models that we were inspired while we had been forming our model, our model framework and finally describes future study opportunities about human and computer interaction analysis and prototyping studies in ERP systems.

\section{Literature review}

Previous researches have produced a long list of factors that seem to influence the use of technology [2]. However, yet, there has been little previous research and models that attempted to demonstrate the factors that are influencing end-user satisfaction with the ERP system and its interface design.

The following model, which is called "Conceptual model of factors affecting end-user satisfaction with ERP systems", was proposed by Calisir \& Calisir [3]. In their research study, the influences of interface usability characteristics, perceived usefulness, and perceived ease of use to end-user satisfaction was explored, if any. 


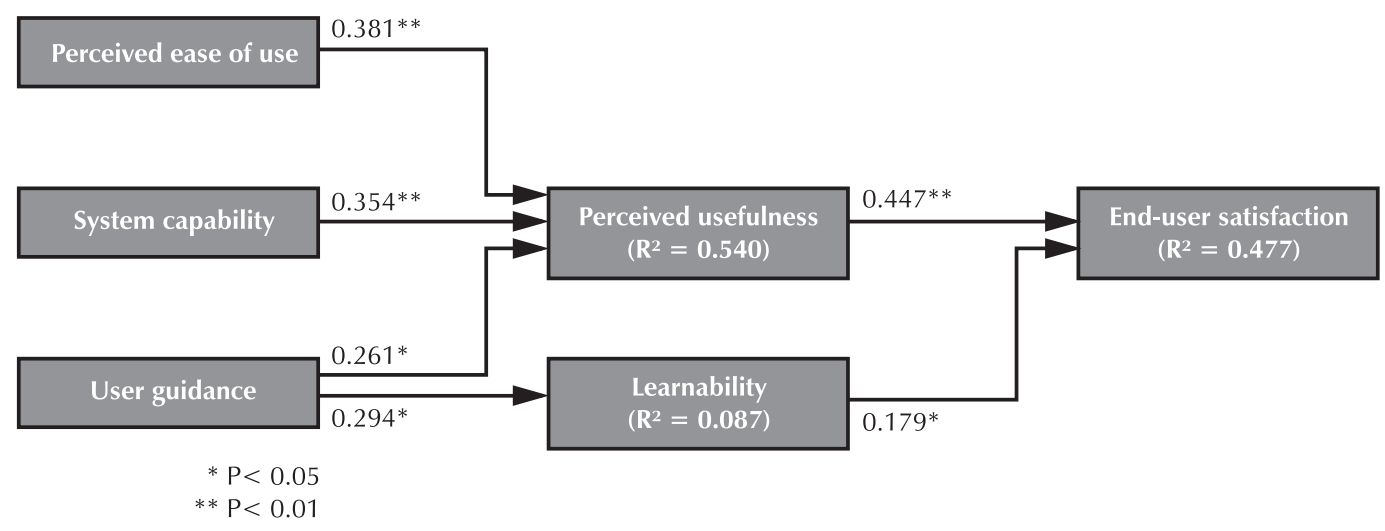

Fig. 1 - A conceptual model of factors affecting end-user satisfaction with ERP systems [3]

The influence of interface usability characteristics, perceived usefulness, and perceived ease of use on end-user satisfaction with enterprise resource planning (ERP) systems is examined and a conceptual model predicting end-user satisfaction with ERP systems was developed in their research. According to their study, the most noticeable aspect of their model is that both perceived usefulness and learnability are determinants of end-user satisfaction with ERP systems. Addition to this, among them, perceived usefulness has the strongest impact on end-user satisfaction [3].

In the next step, "Technology Acceptance Model (TAM)" and "Task-Technology Fit (TTF)" model will be reviewed.

Technology acceptance model (TAM) was proposed by Davis [7]. TAM focuses on attitudes toward using a particular "Information Systems Product" which, users develop based on perceived usefulness and ease of use of the product.

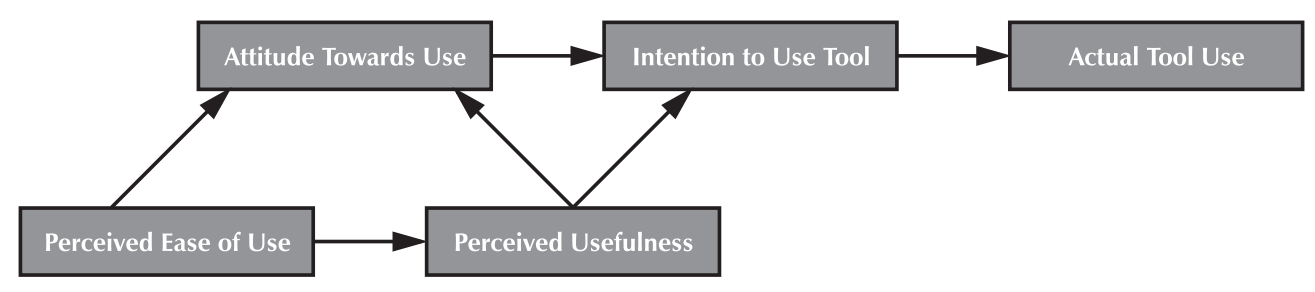

Fig. 2 - Technology Acceptance Model (TAM) [9].

A weakness of TAM alone is that it does not take user task needs into consideration. At this stage, TTF model appears [9]. The core of a TTF Model is a formal construct known as TTF, which is the matching of the capabilities of the technology to the demands of the task, that is, the ability of IT to support a task [11]. 


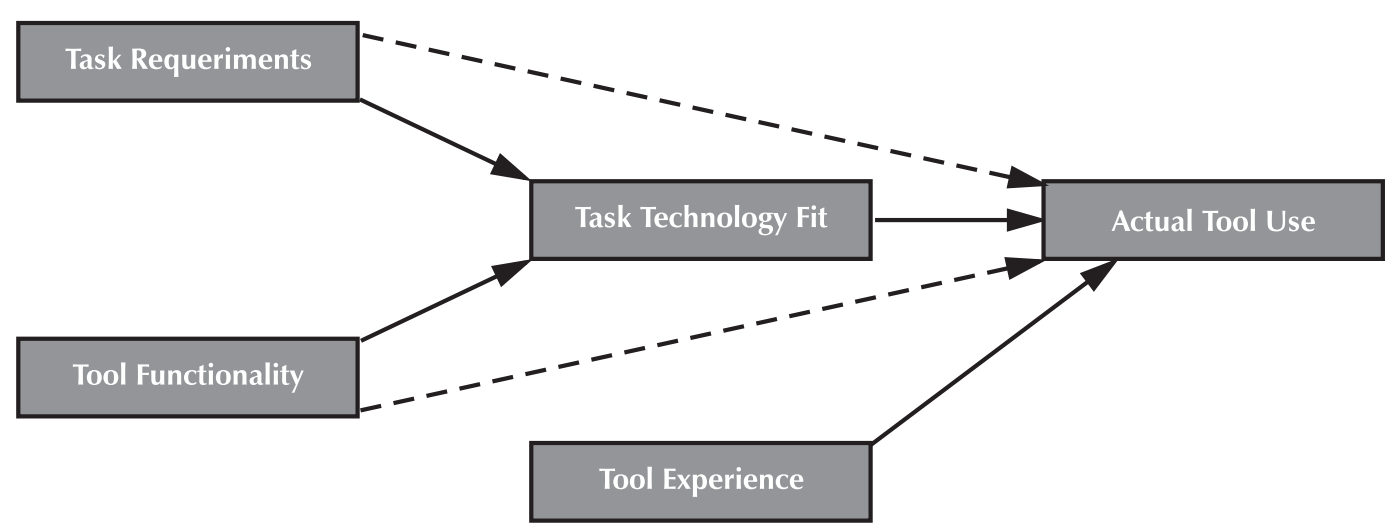

Fig. 3 - Task-Technology Fit (TTF) Model [9].

One approach Dishaw and Strong [9] states is just integrating TAM and TTF in order to explain much more variance in order to understand the user.

\section{Framework}

In our research, the connection between satisfaction, ease of use, usefulness, task-technology fit, navigation, learnability, data quality, minimal memory load, visual factors, flexibility is examined and hypotheses are built up. Fig. 2 illustrates our research model for the factors affecting end-user satisfaction. This model was constructed based on the models that we discussed in literature survey section.

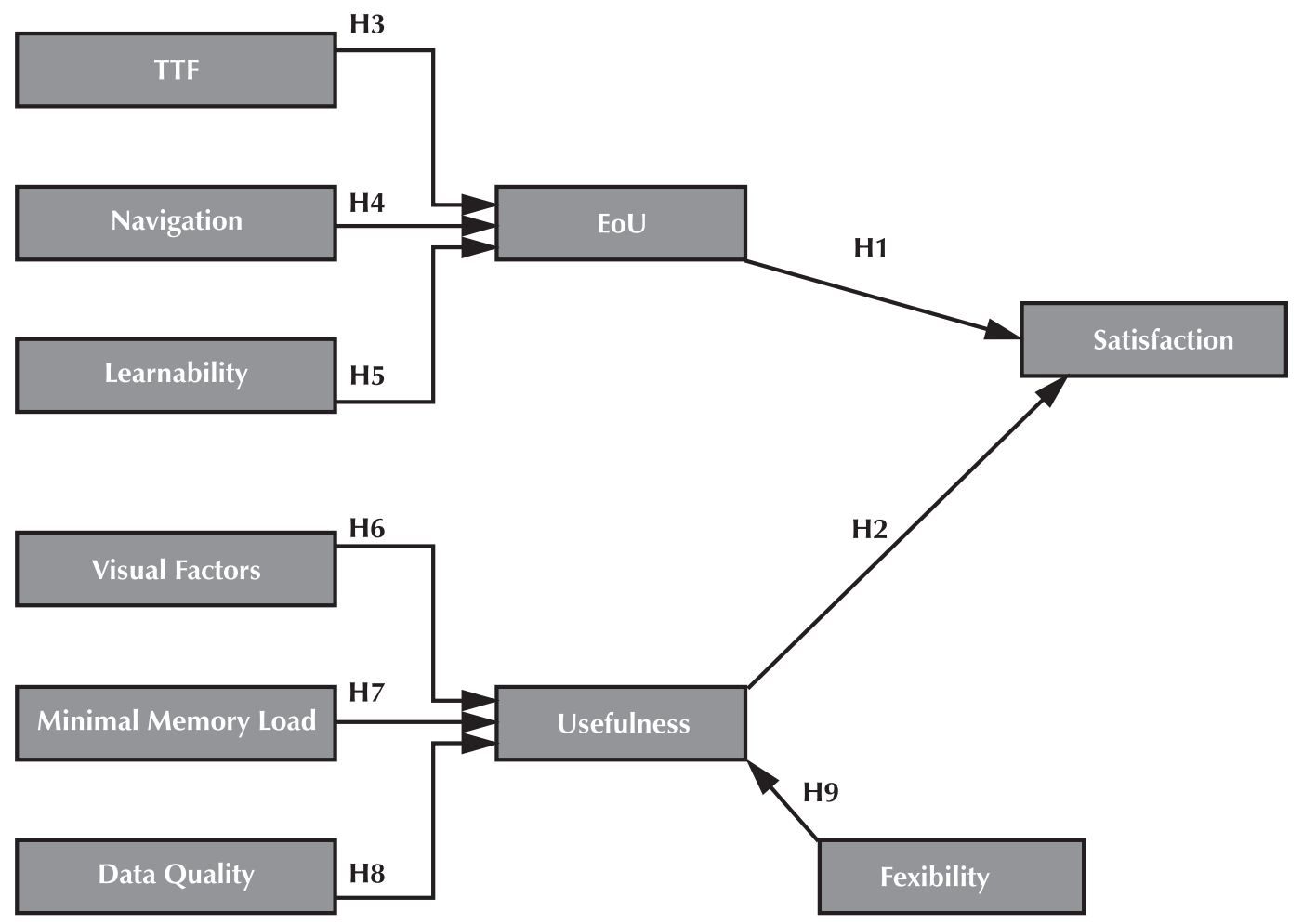

Fig. 4 - Model framework. 
"The degree to which a person believes that using a particular system would be free of effort" is called ease of use. On the other hand, usefulness refers to "the degree to which a person believes that using a particular system would enhance his or her job performance" [6]. Research studies also suggest that perceived usefulness and perceived ease of use is especially important as ways of measuring user satisfaction with IS [21]. Perceived ease of use and perceived Usefulness are assumed to be influencing attitude towards to use and intention to use ERP systems [13]. We consider that end-user is more satisfied when they find the system easy to use and enables them to accomplish their goals.

The first two hypotheses of this study as follows:

$\mathrm{H1}$. Ease of Use significantly and positively influences end-user Satisfaction.

H2. Usefulness significantly and positively influences end-user Satisfaction.

The ability of IT to support a task is expressed by the formal construct known as task-technology, which implies matching of the capabilities of the technology to the demands of the task [11]. Our intention to use task-technology fit construct in our model is that ERP systems will be perceived easy to use and the end-user will be satisfied if the functions available fit the activities of the user. This study hence makes the following inference:

H3. Task-Technology Fit (TTF) significantly and positively influences Ease of Use.

Design of the menu structures affects the user navigation among the modules in ERP systems. Menu structures can prevent end-user to accomplish their tasks. Addition to this, there should be a logic flow in the system. The removal of unnecessary or redundant screens will also help to keep the navigation flow uncomplicated [20]. Based on the above evidence, this study conducts the following hypothesis:

H4. Navigation significantly and positively influences Ease of Use.

Definition of learnability is "Human-computer interaction to be the ease with which new users can begin effective interaction and achieve maximum performance" [10]. We think that learning capability of the ERP system end-user influences their ability to use the system easily. Therefore the following inference is made:

H5. Learnability significantly and positively influences Ease of Use.

Minimal memory load means that the system provides easily recognized, with sufficient and necessary detailed screens and offers simple solutions. On the other hand, visual factors are the user screen characteristics. They are both concerned with usability and interface design. It's known that usability problems may lead directly to a large-scale decrease in end-user satisfaction. For that reason we conduct the following hypotheses to handle the problems and give needed importance to interface design:

H6. Visual Factors significantly and positively influences Usefulness.

H7. Minimal Memory Load significantly and positively influences Usefulness.

There should be qualified data (accurate, reliable, clear, etc.) in the system so that the end-user is satisfied and concerned about the system as useful. For that reason, we hypothesize that:

H8. Data Quality significantly and positively influences Usefulness.

ERP systems should meet every end-users' tasks or give appropriate results with their expectations to satisfy them. To achieve this, mainly, there should be flexibility in the system. Last hypothesis about our research is following:

H9. Flexibility significantly and positively influences Usefulness.

The data were collected from the field using a questionnaire survey to 35 ERP system end-users. Once the data are collected, and then it is analyzed using SPSS software. The questionnaire consisted of two parts. First part is formed to get information about profile of respondents. Second part contained items measuring our model constructs namely, satisfaction, 
ease of use, flexibility, visual factors, usefulness, learnability, data quality, navigation, minimal memory load, task-technology fit. All items from part two were measured using a six-point Likerttype scale with anchors ranging from "strongly disagree" to "strongly agree". The constructs and their items are shown in Appendix A.

\section{Findings $\&$ discussions}

This section discusses the analysis results.

\subsection{Profile of respondents}

The profile of ERP system end-users is presented in Table I. The results indicate that our sample predominantly aged between 26 and 40 and work in different departments. Regarding daily ERP usage, our respondents use ERP system more than five hours a day. And lastly, \%80 of the respondents is well up and has minimum 2 years experience in ERP systems.

Table 1 - Profile of respondents

\begin{tabular}{|l|c|c|}
\hline Question & Frequency & Percentage \\
\hline Age & 4 & 11.4 \\
\hline $21-25$ & 15 & 42.9 \\
\hline $26-30$ & 11 & 31.4 \\
\hline $31-40$ & 5 & 14.3 \\
\hline $41-50$ & 6 & 17.1 \\
\hline Department \\
\hline IT & 4 & 11.4 \\
\hline Finance & 6 & 17.1 \\
\hline Sales & 3 & 8.6 \\
\hline Production & 3 & 8.6 \\
\hline Purchasing & 13 & 37.2 \\
\hline Others & \\
\hline Daily ERP usage & 3 & 8.6 \\
\hline About once a week & 5 & 14.3 \\
\hline About once a day & 11 & 31.5 \\
\hline Less than 4 hours a day & 3 & 8.6 \\
\hline 4 or 5 hours a day & 13 & 37 \\
\hline More than 5 hours a day & & \\
\hline Experience in ERP (year) & 7 & 20 \\
\hline <=2 & 10 & 28.6 \\
\hline 3 & 6 & 34.2 \\
\hline 4-7 & 12 \\
\hline$>=8$
\end{tabular}

\subsection{Instrument validity}

All items from part two of the questionnaire were measured using a six-point Likert-type scale with anchors ranging from "strongly disagree" to "strongly agree". Six-point Likert-type scale was used with the purpose of avoiding central tendency. The constructs and 
their items are shown in Appendix A. In order to prevent or diminish the potential floor effect, all items in the questionnaire were randomly sequenced. Besides, some of the items were worded reversely to ensure the desired balance.

The entire instrument was evaluated in terms of reliability and construct validity. Merely multi-item variables' reliability is analyzed. Instrument validity is presented in Table II. Cronbach's alpha of the all multi-item constructs have values more than 0.66 thus we conclude that the survey had strong internal consistency.

Table II - Instrument validity

\begin{tabular}{|l|c|c|}
\hline Construct & Items & Cronbach's alpha \\
\hline Satisfaction & 4 & 0.87 \\
\hline Usefulness & 3 & 0.89 \\
\hline Ease of Use (EoU) & 2 & 0.76 \\
\hline Visual Factors & 4 & 0.85 \\
\hline Flexibility & 2 & 0.77 \\
\hline Learnability & 4 & 0.67 \\
\hline Navigation & 2 & 0.66 \\
\hline Data Quality & 1 & - \\
\hline Minimal Memory Load & 1 & - \\
\hline Task - Technology Fit (TTF) & 1 & - \\
\hline
\end{tabular}

\subsection{Construct descriptive statistics}

Descriptive statistics of all multi-item constructs are summarized in Table III. The result of the descriptive statistics shows that end-users are satisfied with the system. They find the system uncomplicated to use and valuable. They trust that the system offers high data quality, in other words without redundancy and incorrectness in data. Besides, they consider that ERP system capability matches their requirements and demands. Addition to these, for ERP system users, to remember and reiterate tasks easily is essential. Moreover, they take notice on easy navigation. Lastly, the mean for the learnability construct is below the average. We conclude that they assume that learning the system is not easy. Also, visual factors construct is below the average and inadequate.

Table III - Descriptive statistics

\begin{tabular}{|l|c|c|c|c|}
\hline Construct & Mean & S.D. & Min & Max \\
\hline Satisfaction & 4.75 & 0.80 & 2.75 & 6.00 \\
\hline Usefulness & 4.59 & 0.95 & 2.00 & 6.00 \\
\hline Ease of Use (EoU) & 4.04 & 1.09 & 1.00 & 5.50 \\
\hline Data Quality & 4.49 & 0.74 & 3.00 & 6.00 \\
\hline Task - Technology Fit (TTF) & 4.49 & 1.25 & 2.00 & 6.00 \\
\hline Minimal Memory Load & 4.43 & 1.24 & 1.00 & 6.00 \\
\hline Navigation & 4.26 & 0.96 & 1.50 & 5.50 \\
\hline Flexibility & 4.03 & 1.07 & 2.00 & 6.00 \\
\hline Learnability & 3.99 & 0.77 & 2.00 & 5.25 \\
\hline Visual Factors & 3.91 & 0.97 & 1.50 & 5.25 \\
\hline
\end{tabular}

Rev. Adm. UFSM, Santa Maria, v. I, N. 1, P. 26-36, Jan./ABr. 2008 


\subsection{Our conceptual model}

Result model explains the factors that are affecting end-user satisfaction. Research illustrates that eight of the nine hypotheses were significantly supported. As a result, H9 is not empirically supported in this study. It indicates that the flexibility does not definitely increase the usefulness. Thus, we conclude that ERP system does not have to be flexible for end-users. Except that hypothesis, the model results fit the hypothesized model. Each remaining hypothesized path examines the significance level. A high variance ( $R^{2}$ value) value of each remaining path indicates that the model fits the data well. Figure 5 demonstrates all structural relationships in our model. The figure indicates that variance in end-user satisfaction explained by the model is $\% 69$ which is acceptable.

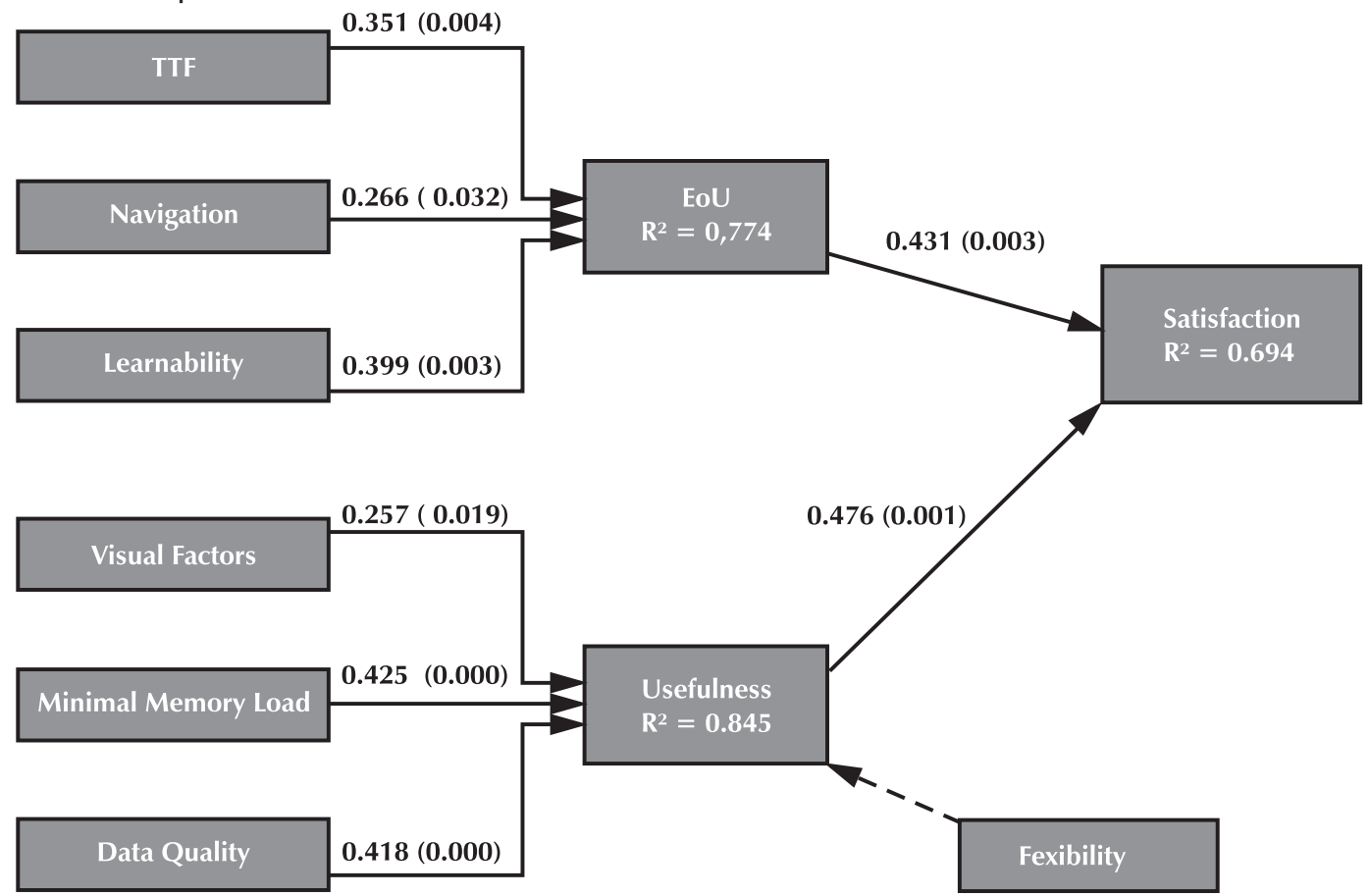

Fig. 5 - Results of the model of the factors that are affecting and-user satisfaction in ERP systems (Significance values in parenthesis)

This model shows that both ease of use and usefulness are determinants of end-user satisfaction. Among all constructs, usefulness has the strongest impact on end-user satisfaction with a $R^{2}=0.845$. Earlier studies confirm the effect of usefulness on end-user satisfaction [3] [6] [8] [12]. "End-users are likely to be more satisfied with IS if they believe that using the system will increase their performance and productivity" [3].

The most noticeable aspect of this model is that minimal memory load has a strong indirect effect on end-user satisfaction via usefulness with a high beta coefficient (0.425). This is a key finding for our future study. Our claim is that end-users find the system more useful and are likely to be more satisfied with the ERP system if and only if they believe that the system provides easily recognized, with sufficient and necessary detailed screens and if offers simple solutions. We took this construct from Calisir \& Calisir [3] model but it is dissimilar that in their study this construct did not take place in their result model. According to Shneiderman \& Plaisant [18], to keep displays simple, to combine multiple-page displays, to reduce window-motion frequency, to allocate sufficient training time for codes, mnemonics, and sequence of actions are required to minimize memory load. In addition to this, codes, abbreviations, and online access to command-syntax forms should be offered. 
Data quality also has a strong impact on usefulness and an indirect influence on end-user satisfaction. Accuracy, timeliness, precision, reliability, currency, completeness, clarity, instructiveness and format of the output are important for data quality [15].

Visual factors as well have an impact on usefulness and an indirect influence on end-use satisfaction. Therefore, for the end-user to find the user-screens comprehensible is especially important. Developers should be aware of the importance of user screen characteristics and user interface design. Usability can significantly reduce training costs, interfere productivity, or making it harder for users to achieve goals as effectively or efficiently as is desirable [1].

Ease of use has a minor but significant impact on end-user satisfaction than usefulness. According to Chadhar \& Rahati [4], the literature has revealed that user satisfaction significantly related to ease of use. In addition to this, Calisir \& Calisir [3] states that both useful and easy to use systems should be designed for ERP systems to be successful.

Indirect impacts of end-user satisfaction on ease of use are task-technology fit, navigation and learnability. Among these learnability has the strongest impact.

In our model, learnability has an indirect pressure in contrast to the study of Calisir \& Calisir [3]. In their study, learnability, along with perceived usefulness, directly influences end-user satisfaction. One way or another, learnability is important for user satisfaction thus occurred in both models. System complexity should be reduced in order to obtain easy learnability.

Another significant finding of this study relates to the effects of task-technology fit on end-user satisfaction through ease of use. Research studies emphasize the need for data to fit the needs of user tasks [17] [19]. Problem solving works best when the problem representation and any tools or aids all support the processes required to perform that task [17].

Navigation has the smallest beta coefficient in our model and has an indirect impact on end-user satisfaction through ease of use. Menu structures should be comprehensible for user to perceive the system usage easy. Narrow and deep menu structures should not be preferred. Removal of unnecessary or redundant screens will help to keep the navigation flow uncomplicated [3].

\section{Conclusion \& future study}

As a result of this research, usefulness and ease of use are the determinants, and task-technology fit, navigation, learnability through ease of use, visual factors, minimal memory load, data quality through usefulness are the indirect impacts of end-user satisfaction.

The most noticeable aspect of our research is that minimal memory load has a strong indirect effect on end-user satisfaction via usefulness with a high beta coefficient (0.425). This finding illustrates that end-users find the system more useful and are likely to be more satisfied with the ERP system if and only if there is short memory load. By the term short memory load we mean, system provides easily recognized with sufficient and necessary detailed screens and offers simple solutions. Also, our two other constructs that are concerned with interface design, visual factors and navigation, have an indirect impact on end-user satisfaction. We can conclude that interface design is significantly important for end-user satisfaction. Thus, ERP vendors should take notice of interface design for end-user satisfaction and to achieve competitive advantage in the market. This finding of the research lights the way for our further study.

For future study, according to these findings, adoption of adaptive and intelligent user screens will be assessed. Additional information will be compiled by observing potential users, forming expert panels and user groups meetings. Furthermore, prototypes will be generated and developed until more proper user interface styles are produced. After prototyping development iterations, also users click patterns are analyzed to improve user screens.

Rev. Adm. UfSM, Santa Maria, v. I, N. 1, P. 26-36, Jan./Abr. 2008 


\section{APPENDIX A}

\section{Constructs \& Items}

1. Satisfaction

My current ERP system is satisfactory.

I would recommend this ERP system others.

I would not recommend ERP systems to anybody.

The results on ERP system meet my expectations.

2. Ease of Use (EoU)

I found the use of the ERP system comprehensible.

I found the ERP system easy to use.

3. Flexibility

I can consolidate relevant information as needed in ERP system.

I can arrange data entries and reports as required in ERP system.

4. Visual Factors

I found user screens comprehensible.

ERP system's user screen characteristics (color, font, etc.) are facilitating ERP

system usage.

I did not experience any difficulty in understanding ERP system's interface de signs.

ERP system has interface design which is easy to use.

5. Usefulness

I can accomplish my tasks faster by using ERP system.

ERP system enhances my productivity.

ERP system enables me to reach relevant information faster.

6. Learnability

I learnt ERP system easily.

ERP system's interface designs facilitate my learning.

It was not easy to learn ERP system.

Users in our organization experienced difficulties in learning ERP system.

7. Data Quality

I think ERP system holds all information that I need.

8. Navigation

I think ERP system's menu structure is comprehensible.

I am totally lost while using the system.

9. Minimal Memory Load

ERP system enables me to remember and reiterate easily how to accomplish a task.

10. Task-Technology Fit (TTF)

I think ERP system is appropriate to my tasks. 


\section{References}

[1] BABAIN, T.; WENY, L.; TOPI, H. Identifying usability issues with an ERP implementation, unpublished.

[2] BAILEY, J.E.; PEARSON, S.W. Development of a tool for measuring and analyzing computer user satisfaction, Management Sciences, 29 (5), p. 530-545, 1993.

[3] CALISIR, F.; CALISIR, F. The relation of interface usability characteristics, perceived usefulness, and perceived ease of use to end-user satisfaction with enterprise resource planning (ERP) systems, Computers in Human Behavior, 2004.

[4] CHADAR, M.A.; RAHATI, N. Impact of national culture on ERP system success, Proceedings of the Second Australian Undergraduate Students' Computing Conference, 2004.

[5] DAVENPORT, T.H. Putting the enterprise back into the enterprise system. Harvard Business Review, 76(4), p. 121-132, 1998.

[6] DAVIS, R. D. Perceived usefulness, perceived ease of use, and user acceptance of technology. MIS Quarterly, 13(3), p. 319-340, 1989.

[7] DAVIS Jr., F.D. A Technology acceptance model for empirically testing new end-user systems: theory and results. Unpublished Doctoral Dissertation, Massachusetts Institute of Technology, 1985.

[8] DAVIS, F.D.; BAGOZZI R.P.; WARSHAW, P.R. User acceptance of computer technology: a comparison of two theoretical models.

Management Science, 35, p. 982-1003, 1989.

[9] DISHAW, M.T.; STRONG, D.M. Extending the technology acceptance model with task-technology fit constructs, Information

Management, 1998.

[10] DIX, A.; FINLAY, J.; ABOWD, G.; BEALE, R. Human-computer interaction. Prentice Hall, $p$. 131-137, 1993.

[11] GOODHUE, D. L.; THOMPSON, R. L. Tasktechnology fit and individual performance. MIS Quarterly, 19(2), p. 213-236, 1995.
[12] IGBARIA, M.; GUIMARAES, T.; DAVIS, G. B. Testing the determinants of microcomputer usage via a structural equation model. Journal of Management Information Systems, Management Science, 11, p.87-114, 1995.

[13] KERIMOGLU, O.; BASOGLU, N. A framework for understanding adoption of organizational enterprise resource planning systems. Proceedings of PICMET'05 Conference, 2005.

[14] KUMAR, K.; HILLSGERSBERG, J. V. ERP: experiences and evolution. Communications of the ACM, 43(4), p. 23-26, 2000.

[15] LI, E.Y. Perceived importance of information system success factors: a meta analysis of group differences. Information \& Management, 32(1), p.15-28, 1997.

[16] LONZINSKY, S. Enterprise-wide software solutions: Integration strategies and practices. Addison Wesley, Reading, MA, 1998.

[17] DISHAW, M.T.; STRONG, D.M. Assessing software maintenance tool utilization using task-technology fit and fitness-for-use models. Journal of Software Maintenance: Research and Practice, 10(3), p.151-179, 1998.

[18] SCHNEIDERMAN, B., PLAISANT, C. Designing the user interface, p.75, 2005.

[19] STRONG, D.M. It process designs for improving information quality and reducing exception handling: a simulation experiment. Information \& Management, 31(5), p. 251-263, 1997.

[20] THONG, J. Y. L.; HONG, W.; TAM, K. Understanding user acceptance of digital libraries: what are the roles of interface characteristics, organizational context, and individual differences? International Journal of Human-Computer Studies, 57, p. 215-242, 2002.

[21] VENKATESH, V.; DAVIS, F. D. A model of antecedents of perceived ease of use: Development and test. Decision Sciences, 27, p. 451-481, 1996. 